\title{
Geometrical transformations of reticulated pavilion canopies as a method for structural optimization
}

\author{
Anna Stefańska ${ }^{1, *}$, Anna Mikos ${ }^{2}$, andEwelina Zientała ${ }^{2}$ \\ ${ }^{1}$ Department of Structure Design, Construction and Technical Infrastructure, Faculty of Architecture, Warsaw University of Technology, \\ Poland \\ ${ }^{2}$ Faculty of Architecture, Warsaw University of Technology, Poland
}

\begin{abstract}
The growing need for rational use of natural resources becomes crucial in all sectors of the current economy. Minimizing the use of materials in construction is becoming an important design aspect. One of the interdisciplinary design methods is geometry optimization, which, thanks to modern computational methods, brings the desired material reduction in constructions. The article examines the impact of using the form-finding method on the example of preliminary geometrical optimization of the reticulated structures. The influence of the dynamic relaxation and geometrical transformations in structure optimization and natural resource minimization is examined. The article aims to indicate the impact of optimization aspects on obtaining efficient load-bearing structures. The research was carried out on the example of a small-scale canopy. Case-studies compare fifteen different geometries generated with the use of mathematical and parametric formulas. The study's conclusions indicate that interdisciplinary tools supporting the process of the initial design phase help in architectural design.
\end{abstract}

\section{Introduction}

The 21 st century is characterized by an increasing rationalization of the use of natural resources [1]. The highest materials exploitation is noticeable, among others, in the Architectural, Construction, and Engineering sector [2]. According to sustainable development, postulates and regulations are being developed to significantly improve design and construction qualities and counteract climate changes [3]. The architectural design currently incorporates technological, social, and ecological aspects of humans life [4]. In the initial phase of designing, it is essential to consider the minimization of material consumption and the increase of economic efficiency. The search for optimal structure shaping [5] might be supported by developing new designing methods supported by computational tools. Mathematical algorithms are used in geometry optimization and topological optimization to archive new generations of lighter weight load-bearing structures [4]. Various aspects of ADO (Architectural Design Optimization) are tested in small-scale experimental facilities, such as pavilions, mainly at the stage of form shaping [6]. The research conducted in the article results from an analysis of selected case studies performed by architecture students. The article presents the influence of geometrical transformations on achieving more lightweight pavilion canopies. The case study explores selected ways of optimizing the geometry and its influence on the load-bearing structure profiles. As a result of the research, it has been observed that topological optimization methods are immensely important at every design stage. Its implementation at an early design stage provides the most beneficial solutions.

\section{Background}

The development of the research on optimal curvilinear geometries was implemented into architectural designing in the last century. The search for many designers was then limited by the lack of access to advanced computational programs. While designing geodesic domes, Buckminster Fuller studied the relationships between the mesh' density divisions and the length of individual structure elements and aimed to unify them. Variants were determined mathematically (or by graphic solutions) [7]. Due to the availability of computational tools, in the $21 \mathrm{st}$ century, improvement of design processes is visible. It can be observed in interdisciplinary research at many Universities [6] and in the work of leading architects such as Santiago Calatrava, Norman Foster, and Zaha Hadid. Formfinding allows designers to obtain unique and unrepeatable forms. Creative shaping of small objects such as pavilions is visible, among the other, in Bamboo Pavilion Hong Kong and Bamboo Pavilion Taiwan.

\section{Literature review}

ADO based on multi-criteria parameters is carried out on objects of different scales. It involves the search for

*Corresponding author: anna.stefanska2@pw.edu.pl 

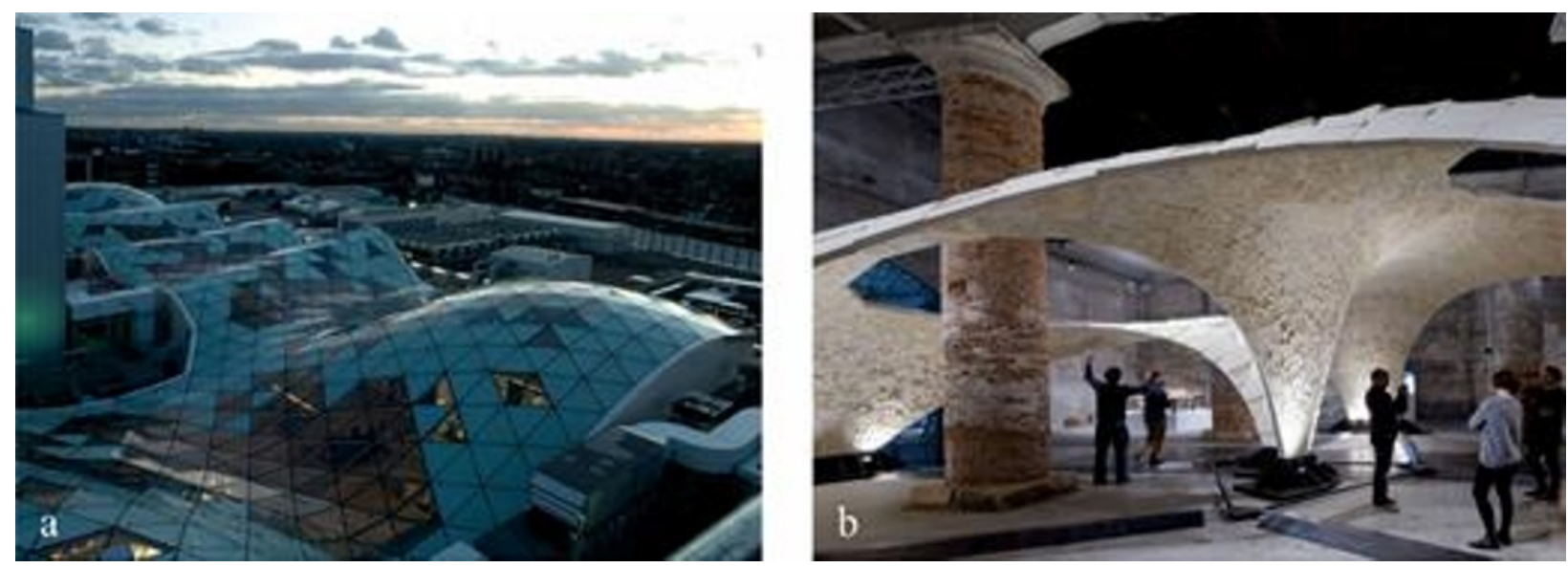

Fig. 1.Examples of using optimization in objects of different scale a) The Westfield Mall, London, Benoy \& Westfield Design Architects, Buchan Group Executive Architects, Ian Richie Architects, 2002-2008; b) Armadillo Vault, Venice, Italy, ETH Zurich, Block Research Group, 2016
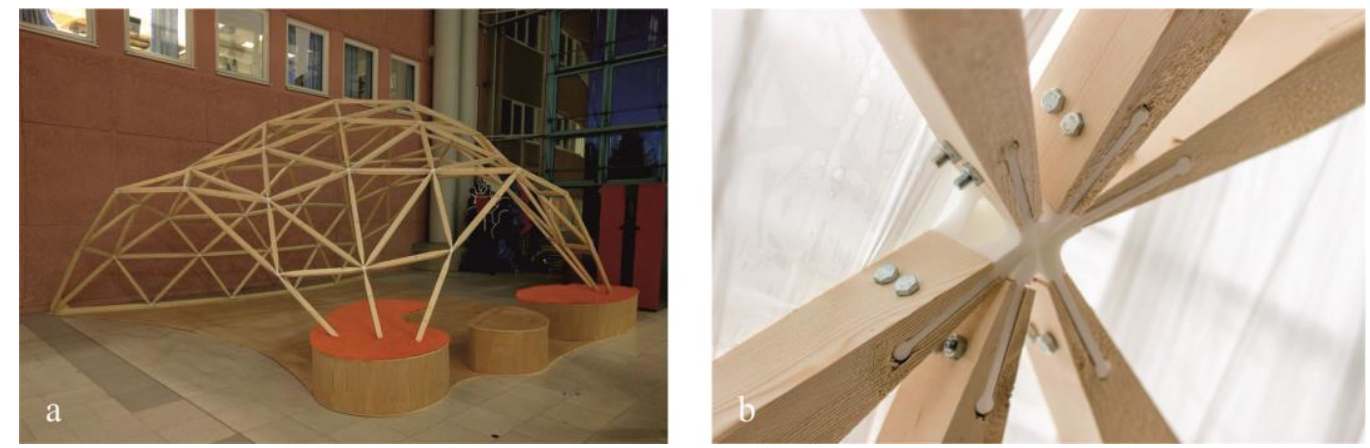

Fig. 2.Example of using optimization in Printshell, NNTU, Additive Manufacturing Lab (Addlab), 2016 a) pavilion) 3D-printed nodes detail

shape (shape-finding) and optimal construction solutions (form-finding) ) [8]. It includes shaping geometry following aesthetic and load-bearing requirements and technological properties of specific materials and reducing production costs [9]. Examples of using the material properties correctly are noticeable in The Westfield Mall, London, Benoy\& Westfield Design Architects, Buchan Group Executive Architects, Ian Richie Architects [8] (steel structures) and Armadillo Vault, Venice, Italy, ETH Zurich, Block Research Group, 2016 (stone structure ) [10].

The design process in contemporary architecture is based on interdisciplinary cooperation. In reticulated structure shaping, close cooperation between the designers, architect, and contractor is essential [11]. Grid-shell structures allow for optimization of load distribution depending on the mesh geometry of the canopy. One aspect of technological optimization simplifies the designed form, e.g., using only single- and double-curved panels or bars in free form structures [12]. The dominant feature of their optimization is load distribution, which defines deformations and internal stresses. In the grid-shell optimization, it is crucial to find a force equilibrium state, which allows determining and optimizing the bar profiles [13].

Researchers conducted structure optimization in the Printshell (realized in 2016 at the Norwegian University of Science and Technology (NTNU); Additive Manufacturing Lab manufactured the joints) using parametric algorithms. The pavilion was designed as a free-form shell, subjected to dynamic relaxation, and optimized for 3D printing fabrication [12]. The ranges of timber member lengths and angles between the elements were algorithmically determined [14]. Adaptation of advanced algorithms in bar structures such as Printshell indicates that the use of parametric optimization methods, among others, might significantly minimize material consumption. In the pavilion, 160 timber elements and 61 printed joints were used(Labonnote, 2016).

\section{Research Methodology}

The analysis aimed to examine the impact of topological transformations on structure optimization, with minimal interference in investigated canopies' aesthetic visual expression. The tests were carried out on the geometry of the steel recirculated roof structure. The primary structural system in all variants remained unchanged: a roof with an area of $750 \mathrm{~m}^{2}$ supported in the corners. Triangular divisions were used, dividing the canopy surface into 64 panels in each case. The scope of the research included the aboveground part of the structure. 

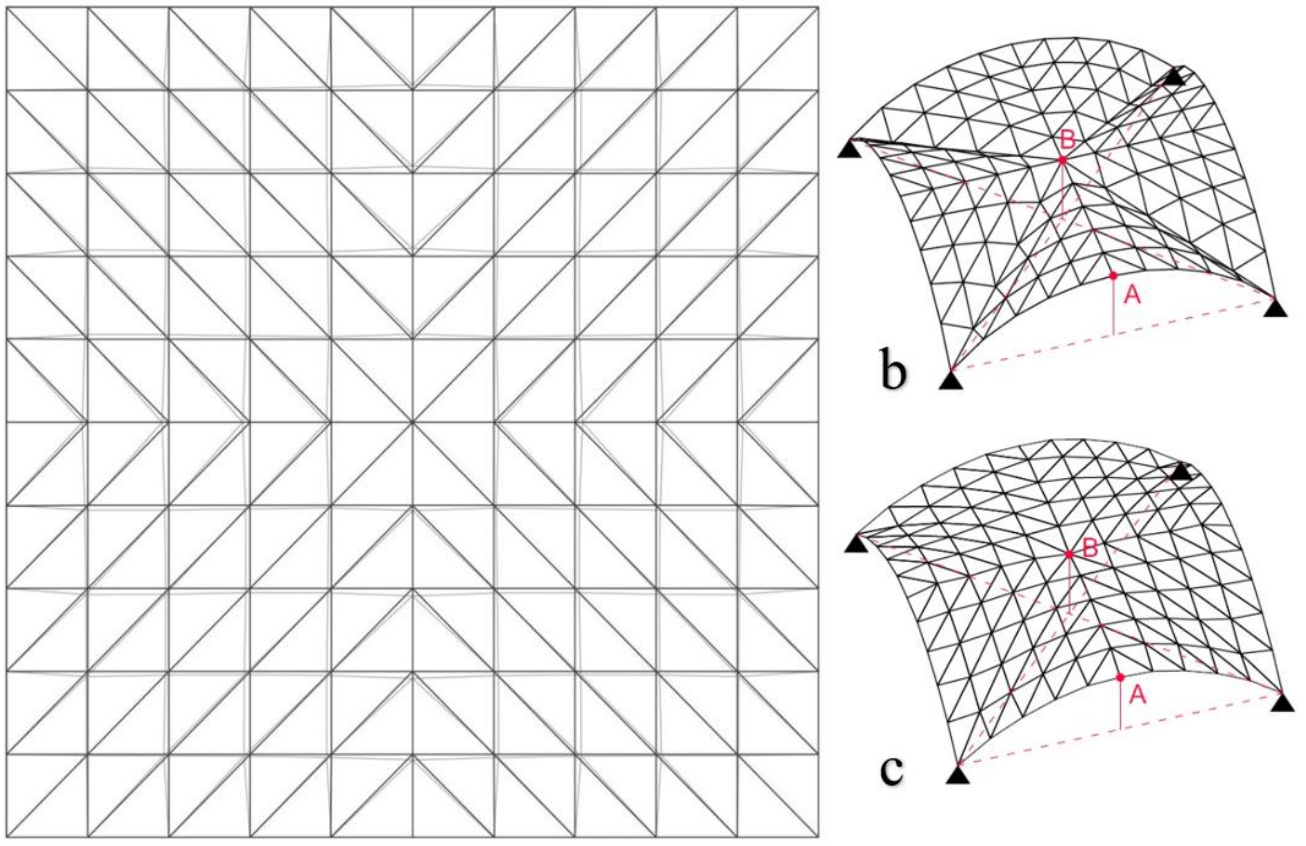

a

Fig. 3. Comparison of analyzed geometries a) comparison of nodes displacements in geometry formed by traditional methods with shaped using generative tools - projection (black color-traditional method, grey color-dynamic relaxation); b) geometry developed using traditional methods, c) geometry developed using generative tools

The study aimed to compare different methods of shaping and optimizing structures. The canopies' geometries were formed using the following tools and methods: mathematical algorithm (using AutoCAD) and generative algorithm (using Grasshopper / Kangaroo). Generative geometries were based on a catenary model and dynamic relaxation algorithms. The profiles of developed geometries were optimized in Robot Structural Analysis. The tests were conducted basing on the dead load, wind load, snow load, service loads, using steel profiles of the S355 class with TRON cross-section. Because in most of the variants, deformations were defining the selection of cross-sections, the maximum deflection followed the formula: 1 / 200 (where 1 - span between supports) due to the use of polycarbonate as the covering material.

The study was divided into two phases. In each phase, the influence of a single variable on the weight of the structure was examined:

Study 1 - analysis of spatial bar structures, with the variable rise of arches located on the edge of the outer contour of the structure; comparing geometries based on a geometric and generative algorithm (Fig. 3b.);

Study 2 - analysis of spatial bar structures with a variable height of the roof midpoint; comparing geometries based on a geometric and generative algorithm (Fig. 3c.).

Fig. 3a.presents a comparison of planarized geometries formed with the use of a geometric and generative algorithm. Visible slight node translations in the $\mathrm{X}$ and $\mathrm{Y}$ axes indicate the catenary model's functions and dynamic relaxation used in the generative algorithm.

\section{Results and Reflection}

\subsection{Results}

Study 1 - The analysis of reticulated spatial structures, the rise of arches located on the edge of the structure's outer contour changes.

Study 1 contains an analysis of 8 variants, differing in the rise of point $\mathrm{A}$, which changed the height of the elevation of arches located in the central part of the edges of the canopy circuit. (Fig.3.b.). The tested variants were compared according to two parameters: total weight and weight-related to a surface square meter.

The study noted that in all variants built using a geometric algorithm (using CAD tools), the optimal cross-section did not change (assuming homogeneity of the structure profiles). The change of cross-section can be noticed in geometry formed with the use of the generative algorithm. The generative variant W.1.4A is about $35 \%$ of the weight of the geometrical variant W.1.4. It demonstrates the benefits of using dynamic relaxation and the catenary model.

Variant W.1.4 was assumed in the next study. With the rise of arches located in the middle of the edges of circuit $6.5 \mathrm{~m}$ as output geometry.

Study 2 - The analysis of reticulated spatial structures, with changes in the height of the midpoint of the structure.

Study 2 contains an analysis of 7 variants, differing in midpoint B's height (Fig. 3.c.). The tested variants 
Table 1.Study 1 - analysis results.

\begin{tabular}{|c|c|c|c|c|c|}
\hline Variant & Point A rise & Point B rise & $\begin{array}{c}\text { Cross- } \\
\text { section }\end{array}$ & $\begin{array}{c}\text { Total weight } \\
{[\mathbf{k g}]}\end{array}$ & $\begin{array}{c}\text { Weight per square meter of } \\
\text { surface }\left[\mathbf{k g} / \mathbf{m}^{\mathbf{2}}\right]\end{array}$ \\
\hline W.1.1 & 4 & 0 & $711 \times 6$ & 107768 & 127,59 \\
\hline W.1.2 & 5 & 0 & $711 \times 6$ & 110133 & 123,10 \\
\hline W.1.3 & 6 & 0 & $711 \times 6$ & 112928 & 118,45 \\
\hline W.1.4 & 6,5 & 0 & $711 \times 6$ & 114611 & 116,27 \\
\hline W.1.5 & 7 & 0 & $711 \times 6$ & 116316 & 114,03 \\
\hline W.1.6 & 8 & 0 & $711 \times 6$ & 120117 & 109,81 \\
\hline W.1.7 & 9 & 0 & $711 \times 6$ & 124370 & 105,92 \\
\hline W.1.4A & 6,5 & 0 & $323,9 \times 5$ & 39930 & 51,42 \\
\hline
\end{tabular}

Table 2.Study 1 - analysis results.

\begin{tabular}{|c|c|c|c|c|c|}
\hline Variant & Point A rise & Point $B$ rise & $\begin{array}{l}\text { Cross- } \\
\text { section }\end{array}$ & $\begin{array}{c}\text { Total weight } \\
{[\mathrm{kg}]}\end{array}$ & $\begin{array}{c}\text { Weight per square meter of } \\
\text { surface }\left[\mathrm{kg} / \mathrm{m}^{2}\right]\end{array}$ \\
\hline W.2.1 & 6,5 & 1 & $610 \times 6,3$ & 101403 & 105,60 \\
\hline W.2.2 & 6,5 & 2 & $406,4 \times 6$ & 63631 & 67,89 \\
\hline W.2.3 & 6,5 & 3 & $273 \times 5$ & 35193 & 38,37 \\
\hline W.2.4 & 6,5 & 4 & $219,1 \times 5$ & 27996 & 31,11 \\
\hline W.2.5 & 6,5 & 5 & $193,7 \times 5$ & 24622 & 27,80 \\
\hline W.2.6 & 6,5 & 6,5 & $168,3 \times 5$ & 21210 & 24,35 \\
\hline W.2.6A & 6,5 & 6,5 & $244,5 \times 5$ & 30428 & 38,08 \\
\hline \multirow[t]{3}{*}{ W.2.6o } & 6,5 & 6,5 & $114,3 \times 4$ & 13241 & 15,20 \\
\hline & & & $139,7 \times 5$ & & \\
\hline & & & $168,3 \times 5$ & & \\
\hline \multirow[t]{3}{*}{ W.2.6Ao } & 6,5 & 6,5 & $127 \times 4$ & 13686 & 17,12 \\
\hline & & & $159 \times 4,5$ & & \\
\hline & & & $244,5 \times 6$ & & \\
\hline
\end{tabular}

were compared according to 2 parameters: total weight of the structure and weight per square meter of surface. The search for point B's height was carried out in the range from 1.0 to $6.5 \mathrm{~m}$ (for aesthetic reasons, the upper limit was assumed as the height equal to point's A height).

As a result of the transformations, the tested parameters: total weight of the structure and weightrelated to a square meter of the surface area improved significantly. The lightest geometry shaped by the geometric method was the W.2.6 variant, which was afterward compared with the geometry built based on the generative model. Basing on the same boundary conditions, Variant W2.6 achieved a ratio of weight to surface $36 \%$ better than Variant W.2.6A.

Due to the inconclusive indication, which of the shaping methods is more optimal, additional material optimization was carried out. The homogeneity of the structures has been replaced by the possibility of optimizing cross-sections in 3 groups of cross-sections depending on the degree of bar effort, resulting in a significant total weight reduction. A similar overall weight was obtained in both variants in more in-depth multi cross-section bar optimization in structures (with the divisions for three types of profiles).

\subsection{Reflection}

Generative methods can be helpful, but they do not need to replace traditional methods based on empirical research entirely. Conscious forming of structures shaped by geometric methods allows achieving results similar to simple generative algorithms. A crucial aspect of using generative tools is that geometries shaped with this method achieve higher aesthetic value through biomimetic patterns, with simultaneous optimal structural forms.

\section{Discussion and Conclusion}

\subsection{Discussion}

Nowadays, the shaping of grid-shell brings endless possibilities of creating architectural forms, in which the load-bearing elements become part of the aesthetic expression of the object [15]. Conducted at the early stage of geometrical design optimizations, impacts structural adaptability to boundary conditions. Topological optimization is a modern design tool that allows efficient shaping structures, with simultaneous parameter modification of the initial shape and final form [16]. The studies indicate that small changes do not have to affect the functional arrangement of the object. The reticulated structures presented in the research show efficiency variations in the analyzed load systems, based on their geometric variability. According to the principle of "form follows material" [17], small visual changes at the early stage of designing, based on algorithmization tools for optimization, allow for a 
combination of structural logic and architectural aesthetics. The relationship between form and material has already been noticed by Frank Lloyd Wright, who claimed that the language of design, the way an object is shaped, is closely related to the material used, and an "Appropriate designs for one material would not be at all appropriate for any other material" [18].

\subsection{Conclusion}

Topological optimization research is increasingly available through digital tools from the early design stage to fabrication technologies. The development of tools supporting the computational design and digital fabrication allows expanding interdisciplinary cooperation possibilities to shape significantly and optimize geometries [19]. Insufficient knowledge of computational tools slows down the industry development pace. As a result, on a larger scale, their use in the industry is not visible [20]. The study purposes were to draw attention to opportunities that are still to be exploited in free-form canopies optimization [21]. The study intended to research carried out shows a tendency that, with simple optimization assumptions, it is possible to reduce the structure's total weight rationally within the students' project.

\section{References}

[1] J. Marchwiński, K. Zielonko-Jung, Contemporary pro-environmental architecture (Warszaw, Polish Scientific Publishers PWN, 2012)

[2] N. Cortiços, Self-learning ang Self-repairing Technologies to Establish Autonomous Building Maintenance, in 2nd International Conference on Building Materials and Materials Engineering (2018)

[3] European Commission, The European construction sector: a global partner (2016)

[4] T. Kotnik, Research culture in architecture, Cross-Disciplinary Collaboration, C. Leopold, C. Robeller and U. Weber, Eds. (Berlin/Boston: Birkhauser, 2020) 183-192

[5] A. Vasilkin, Possibilities of applying structural optimization in building structures computeraided design systems, in MATEC Web of Conferences (2018)

[6] A. Stefańska, Generative design in the architecture of exhibition pavilions, Vistula University Working Papers 57, 6, 82-89 (2017)

[7] R.B. Fuller, Patent 2, 682, 235 (1954)

[8] F. Scheible, M. Dimcic, Parametric Engineering Everything is Possible, in 35th Annual Symposium of IABSE / 52nd Annual Symposium of IASS (2011)

[9] M.I. Ali, F. Fan, P.N. Khakina, H.H. Ma, CostEffective Design of Space Structures Joints: A,
International Journal of Structural and Construction Engineering 7, 1 (2013)

[10] P. Block, M. Rippmann, T. Van Mele, D. Escobedo, The Armadillo Vault: Balancing computation and traditional craft, FABRICATE, 286-293 (2017)

[11] J. Chilton, G. Tang, Timber gridshells: architecture, structure and craft (London: London and New York: Routledge, 2017) 28

[12] S.H. Dyvik, M. Luczkowski, J.H. Mork, A. Rønnquist, B. Manum, Design of freeform gridshell structures - Simplifying the parametric workflow, in IABSE Symposium 2019 Guimarães: Towards a Resilient Built Environment - Risk and Asset Management, Guimarães (2019)

[13] S.H. Dyvikand, J.H. Mork, Gridshell manual (Trondheim, Norway, 2015)

[14] N. Labonnote, PrintShell (2016) [Electronic resource] Available at: https://www.ntnu.edu/kt/research/csdg/research/p rintshell

[15] N. Buzalo, S. O. Versilov, I. Platonova, N.G. Tsaritova, Energy efficient building structures based on gridshell, in IOP Conference Series: Materials Science and Engineering (2019)

[16] A. Nowak, W. Rokicki, Model test for topologically transformed rod structures, Space, Economics, Society, 209-215 (12 February 2017)

[17] I. Röstlund, Form follows material, Design with local resources (Gothenburg, Sweden: Master Tesis, Department of Architecture and Civil Engineering, Chalmers University of Technology, 2017)

[18] F.L. Wright, The Future of Architecture (New York: Horizon Press, 1953) 23

[19] S. Adriaenssens, A. Menges, M. Pauly, D. Pigram, F. Gramazio, M. Kohler, O. Kasap, R. Loveridge, Advances in Architectural Geometry (2016)

[20] S. Dixit, K. Sharma, An Empirical Study of Major Factors Affectiong Productivity of Construction Projects, in Emerging Trents in Civil Engineering, Lecture Notes in Ciliv Engineering (Singapore, Springer, 2020)

[21] J. Caigui, F. Gunther, J. Wallner, H. Pottman, Measuring and Controlling Fairness of Triangulation, in Advances in Architectural Geometry (2016) 